\title{
Oxygen isotopes as a valuable tool for measuring annual growth in tropical trees that lack distinct annual rings
}

\author{
ChenXI Xu, ${ }^{1 *}$ Masaki Sano, ${ }^{1}$ KeI Yoshimura ${ }^{2}$ and TAKeshi NAKatsuKa ${ }^{1}$ \\ ${ }^{1}$ Research Institute for Humanity and Nature, Motoyama, Kamigamo, Kita-ku, Kyoto 603-8047, Japan \\ ${ }^{2}$ Atmospheres and Ocean Research Institute, The University of Tokyo, Tokyo 277-8564, Japan
}

(Received January 7, 2014; Accepted April 9, 2014)

\begin{abstract}
Some trees from tropical areas lack visually detectable and consistent annual growth rings. As such, we have measured the radial variation of cellulose oxygen isotopes in trees that grow in seasonally dry forests of Northern Laos to explore the possibility if this method can be used for the identification of annual rings. One disk from a 7-year-old Styrax tonkinensis (S. tonkinensis) in plantation and two cores from two Ficus semicordata var. semicordata (F. semicordata) in forests were examined. High-resolution cellulose oxygen isotopes of $S$. tonkinensis and F. semicordata show clear cycles with amplitudes of 5\%o and 9\%o, respectively. To further test if the oxygen isotope cycles that we observed are annual or not, a tree ring cellulose oxygen isotope model is employed. Input data of the model are relative humidity and modeled precipitation $\delta^{18} \mathrm{O}$. The modeling results independently support our detection of oxygen isotope annual cycles. Therefore, we conclude that tree ring cellulose oxygen isotopes have great potential to identify annual rings in tropical trees, which typically lack distinct annual rings in the context of seasonal climate.
\end{abstract}

Keywords: tropical tree with non-distinct annual rings, cellulose oxygen isotopes, fractionation model, Styrax tonkinensis, Ficus semicordata var. semicordata

\section{INTRODUCTION}

Tropical forests contain roughly $25 \%$ of the carbon in the terrestrial biosphere, therefore, research on the responses of tropical forests to global change is critical in predicting future global carbon cycling (Bonan, 2008). To date, such research has primarily been focused at the leaf and community level, and studies on long-term changes at the individual tree and population levels are needed (Zuidema et al., 2013). However, tropical trees often fail to develop reliable annual rings, because many species lack visible tree rings or have only indistinct ring patterns. As such, it is difficult to estimate the age and growth rate of tropical trees. This information is essential for understanding the forest development process and forest response to global change, and is also useful for reconstructing past climate. Therefore, developing a method for estimating the annual growth pattern of such trees with non-distinct rings is important. Dendrometer can measure the radial growth rate of tropical trees by continuous measurements of diameter growth (da Silva et al., 2002; Ohashi et al., 2005). However, the dendrometer method cannot provide tree's growth rate

\footnotetext{
*Corresponding author (e-mail: xuchenxi@gmail.com)

Copyright (c) 2014 by The Geochemical Society of Japan.
}

prior to the marking period.

Another method to measure growth of trees is to detect the periodicity of wood formation. Tree ring cellulose oxygen isotopes $\left(\delta^{18} \mathrm{O}\right)$ are mainly controlled by soil water $\delta^{18} \mathrm{O}$ and relative humidity (Roden $e t$ al., 2000). In tropical areas with distinct rainy and dry seasons, the amount of precipitation shows clear seasonality, and generally relative humidity and precipitation $\delta^{18} \mathrm{O}$ has a positive and negative correlation (amount effect) with the amount of rainfall in tropical regions (Araguas-Araguas et al., 1998; Dansgaard, 1964). ${ }^{18} \mathrm{O}$-depleted precipitation and high relative humidity in the rainy season results in lower tree ring cellulose $\delta^{18} \mathrm{O}$, and vice versa in the dry season. Such seasonal cycles of precipitation $\delta^{18} \mathrm{O}$ and relative humidity may generate seasonal cycles of tree ring cellulose $\delta^{18} \mathrm{O}$, which can be used to identify annual growth (Anchukaitis et al., 2008; Anchukaitis and Evans, 2010; Evans and Schrag, 2004; Poussart and Schrag, 2005). To date, however, no such study has been performed in northern Southeast Asia.

In this study, we measured tree ring cellulose $\delta^{18} \mathrm{O}$ for three cores in total, collected from two species in plantation and natural forest, respectively in northern Laos in order to: (1) further investigate the potential of oxygen isotopes in the identification of annual growth in trees that have no anatomically distinct rings; (2) cross-check the periodicity between different tree species. 


\section{Tree ring Cellulose OXygen Isotope Model}

During the process of taking soil water by tree roots there is no isotopic fractionation (White et al., 1985). The xylem water is then transported to the leaves, where leaf water is subject to evaporation that results in isotopic enrichment, which is controlled by the relative humidity of the ambient environment (Barbour et al., 2004; Roden et al., 2000). This process is described by the equation of Craig and Gordon (1965):

$$
\delta^{18} \mathrm{O}_{1}=\delta^{18} \mathrm{O}_{\mathrm{s}}+\varepsilon^{*}+\varepsilon_{k}+e_{\mathrm{a}} / e_{\mathrm{i}}\left(\delta^{18} \mathrm{O}_{\mathrm{a}}-\varepsilon_{k}-\delta^{18} \mathrm{O}_{\mathrm{x}}\right)
$$

where the subscripts $1, \mathrm{~s}, \mathrm{x}$, and a refer to leaf water, source water, xylem water and water vapor in the air outside the leaf, respectively, $\varepsilon^{*}\left(\varepsilon_{k}\right)$ is the equilibrium (kinetic) isotopic fractionation factor, and $e_{\mathrm{a}}\left(e_{\mathrm{i}}\right)$ is the ambient (intercellular) vapor pressure. However, the $\delta^{18} \mathrm{O}$ of leaf water is often not as enriched as predicted by the Craig-Gordon model (Allison et al., 1985; Flanagan and Ehleringer, 1991; Flanagan et al., 1991). Barbour et al. (2004) improved the Craig-Gordon model to include the potential influence of the Péclet effect, where diffusion of ${ }^{18} \mathrm{O}$ enriched water away from the sites of transpiration in the leaves back into the ${ }^{18} \mathrm{O}$-unenriched xylem water leads to lower $\delta^{18} \mathrm{O}$ for bulk leaf water than predicted from a simple calculation based only on the evapotranspiration site. The bulk leaf isotopic composition is predicted by the following equation (Sternberg, 2009):

$$
\delta^{18} \mathrm{O}_{\mathrm{L}}=(1-\alpha) \delta^{18} \mathrm{O}_{\mathrm{s}}+\alpha \delta^{18} \mathrm{O}_{1}
$$

where $\delta^{18} \mathrm{O}_{\mathrm{L}}$ represents the $\delta^{18} \mathrm{O}$ of bulk leaf water and $\alpha$ is the fraction of enriched water.

Then, carbohydrate that records the water $\delta^{18} \mathrm{O}$ is produced in the leaves by combining water and carbon dioxide during the process of photosynthesis. After carbohydrates formation, it is then transported to the trunk where a fraction of the oxygen atoms from sucrose undergo isotopic exchange with xylem water during cellulose synthesis. Tree ring cellulose oxygen isotope is then calculated as:

$$
\delta^{18} \mathrm{O}_{\mathrm{c}}=f_{0}\left(\delta^{18} \mathrm{O}_{\mathrm{s}}+\varepsilon_{\mathrm{o}}\right)+\left(1-f_{0}\right)\left(\delta^{18} \mathrm{O}_{\mathrm{L}}+\varepsilon_{\mathrm{o}}\right)
$$

where $\delta^{18} \mathrm{O}_{\mathrm{c}}$ represents the $\delta^{18} \mathrm{O}$ of tree ring cellulose, $f_{\mathrm{o}}$ is the exchanged proportion of carbohydrate oxygen with xylem water, and $\varepsilon_{\mathrm{o}}$ is the net biological isotopic fractionation factor between the xylem water and the exchanged oxygen in the carbohydrate.

During the whole process, it is generally assumed that atmospheric vapor is at equilibrium with xylem water and

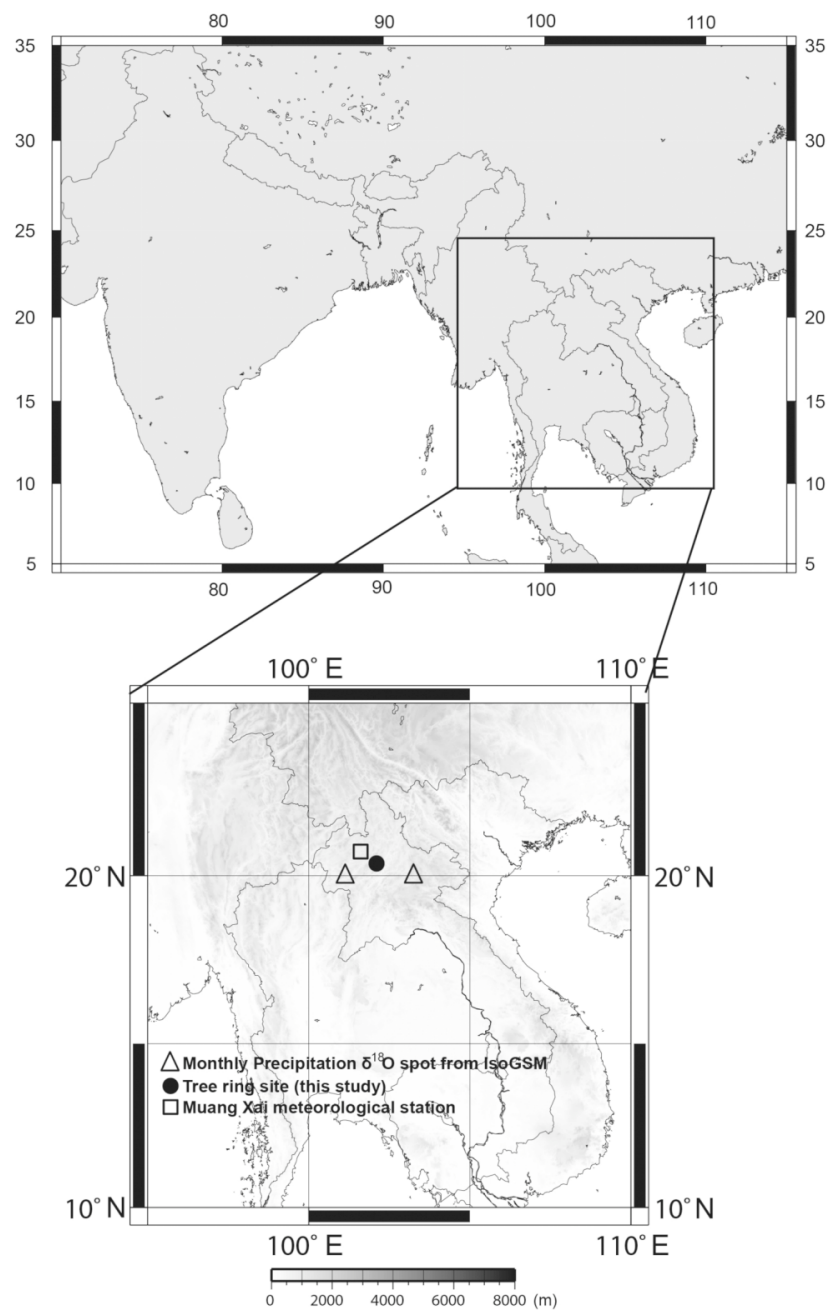

Fig. 1. The study region, showing the locations of the Kachet village (black spot), the Muang Xai meteorological station (square) and monthly modeled precipitation oxygen isotope grid point (triangle).

that leaf temperature follows the ambient temperature. Based on these assumptions, $\delta^{18} \mathrm{O}_{\mathrm{a}}$ can be equal to $\delta^{18} \mathrm{O}_{\mathrm{p}}$ $-\varepsilon^{*}$ and $e_{\mathrm{a}} / e_{\mathrm{i}}$ be equal to the relative humidity $(h)$ (Dongmann et al., 1974). The cellulose oxygen isotopic ratio is expressed as (Sternberg, 2009):

$$
\delta^{18} \mathrm{O}_{\mathrm{c}}=\left(\delta^{18} \mathrm{O}_{\mathrm{s}}+\varepsilon_{\mathrm{o}}\right)+\alpha\left(1-f_{0}\right)(1-h)\left(\varepsilon^{*}+\varepsilon_{k}\right)
$$

\section{METHODS AND MATERIALS}

\section{Sampling site and local climate}

To test the stable isotope chronometer in samples lacking ring structure, but from a region with distinct rainfall seasonality, we collected two cores of $F$. semicordata in 


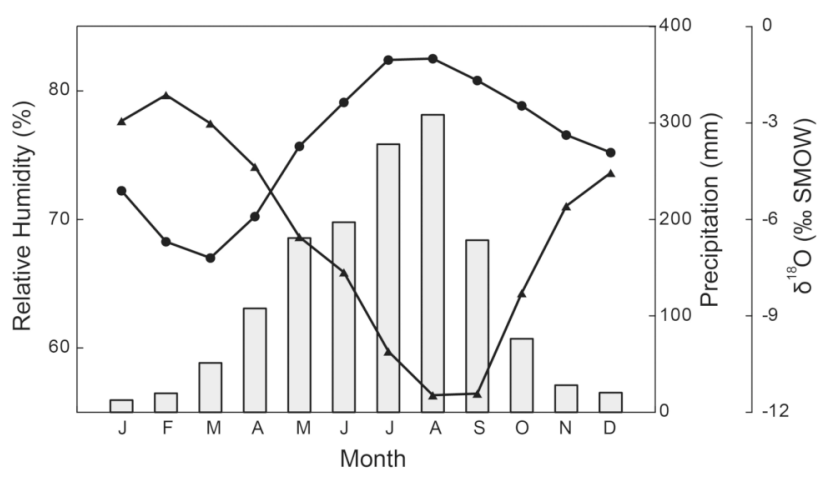

Fig. 2. Monthly relative humidity (black spot), precipitation (gray bar) between 1991 and 2010 at the Muang Xai instrumental station, and monthly modeled precipitation $\delta^{18} \mathrm{O}$ (black triangle) from two grid points (Yoshimura et al., 2008).

natural forests using a $12 \mathrm{~mm}$ diameter increment borer at breast height, and one disk of S. tonkinensis from a plantation near Kachet village, Luang Prabang, Laos $\left(20.5^{\circ} \mathrm{N}, 102.3^{\circ} \mathrm{E}, 800 \mathrm{~m}\right.$ asl; Fig. 1) in August 2011. We select $S$. tonkinensis in the plantation for our research, because we can know the exact age of Styrax tonkinensis based on the local villagers. So we can test if the age of $S$. tonkinensis that is measured by our method is right. There is a distance of $c a .1 \mathrm{~km}$ from the natural forests to the plantation. According to 1991-2010 meteorological data (Fig. 2) from the Muang Xai weather station $\left(20.7^{\circ} \mathrm{N}\right.$, $102^{\circ} \mathrm{E}$ ), which is located $40 \mathrm{~km}$ northwest of Kachet village, the mean annual temperature is $23^{\circ} \mathrm{C}$ and the mean annual precipitation is $1460 \mathrm{~mm}$, of which $78 \%$ falls in the rainy season (May-September). In addition, relative humidity is higher in the monsoon season (MaySeptember) and lower in the dry season (November-April) (Fig. 2).

F. semicordata (Figs. 3a and b; Ka-018 and -019) has apparent growth rings, whereas $S$. tonkinensis (Fig. 3c; $\mathrm{Ka}-\mathrm{d})$ has non-distinct ring boundaries. In order to identify tree ring cellulose $\delta^{18} \mathrm{O}$ cycles, we measured stable isotopes in $S$. tonkinensis at $1 \mathrm{~mm}$ resolution. To test whether or not the apparent rings of $F$. semicordata are annual in nature, we analyzed tree ring oxygen isotopes of the two cores in the apparent rings. We can assume that tree ring cellulose $\delta^{18} \mathrm{O}$ of the two trees should be highly correlated if the apparent rings of $F$. semicordata are actual annual rings, based on previous studies of tree ring cellulose $\delta^{18} \mathrm{O}$ of Fokienia hodginsii from northern Laos, Vietnam and southern China (Sano et al., 2012; Xu et al., 2011, 2013a, 2013b). We measured 50 and 184 rings for Ka-018 and Ka-019, respectively. The age of the $F$. semicordata from the natural forest is unknown, whereas the $S$. tonkinensis in the plantation is 7 years old.

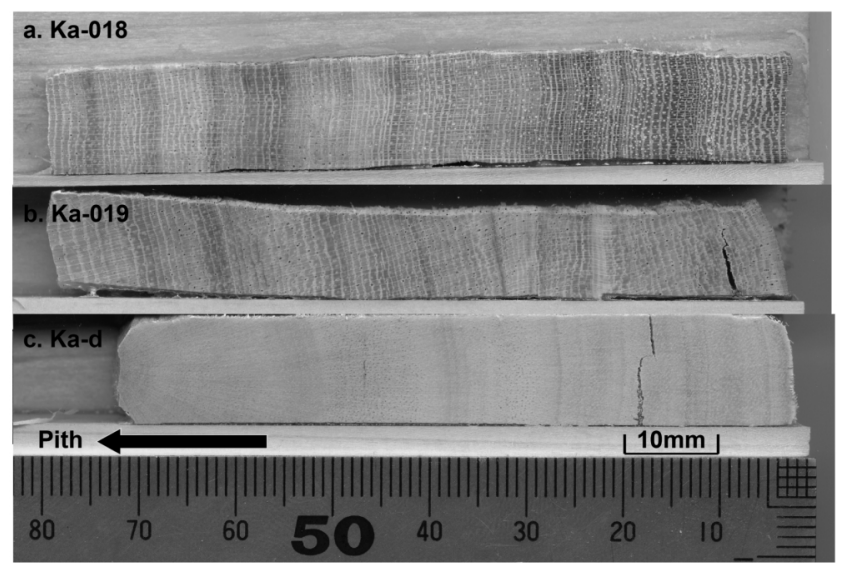

Fig. 3. Photo of sample for Styrax tonkinensis (Ka-d) and Ficus semicordata var. semicordata (Ka-018 and 019).

\section{Cellulose extraction}

To reduce the time required for sample preparation, we used the plate method (Xu et al., 2011) to extract $\alpha$ cellulose from the tree cores, which generally involves the chemical protocol of the Jayme and Wise method (Green, 1963; Loader et al., 1997). The main feature of the plate method is that $\alpha$-cellulose is extracted directly from the wood plate, rather than from individual rings (i.e., wood segments or powders). Due to wood shrinkage during the process of chemical treatment, a simple method to maintain the $1 \mathrm{~mm}$ resolution of the original sample was employed, whereby we measured the length of the original wood $\left(\mathrm{L}_{\mathrm{o}}\right)$ and cellulose plates $\left(\mathrm{L}_{\mathrm{c}}\right)$, then calculated the ratio of shrinkage $\left(\mathrm{L}_{\mathrm{c}} / \mathrm{L}_{\mathrm{o}}\right)$, and subsequently cut samples from the cellulose plate under a microscope with a resolution of $\mathrm{L}_{\mathrm{c}} / \mathrm{L}_{\mathrm{o}} \mathrm{mm}$.

\section{Isotope measurements}

Oxygen isotope ratios $\left({ }^{18} \mathrm{O} /{ }^{16} \mathrm{O}\right)$ of the cellulose samples were determined with a continuous flow system using an isotope ratio mass spectrometer (Delta Plus XL and Delta V ADVANTAGE) interfaced to pyrolysis-type elemental analyzers (TC/EA) at the Research Institute of Humanity and Nature (Kyoto, Japan) and Graduate School of Environmental Studies of Nagoya University (Nagoya, Japan). Cellulose $\delta^{18} \mathrm{O}$ values were calculated by comparison to the Merck cellulose laboratory working standard, which was analyzed frequently during the measurement of the tree cellulose samples. Oxygen isotope results are presented in the $\delta$ notation as the per mil (\%o) deviation from the international stable oxygen isotope standard Vienna Standard Mean Ocean Water (VSMOW): $\delta^{18} \mathrm{O}=\left[\left(\mathrm{R}_{\text {sample }} / \mathrm{R}_{\text {standard }}\right)-1\right] \times 1000$, where $\mathrm{R}_{\text {sample }}$ and $\mathrm{R}_{\text {standard }}$ are the ${ }^{18} \mathrm{O} /{ }^{16} \mathrm{O}$ ratios of the sample and standard, respectively. The analytical uncertainties for repeated 


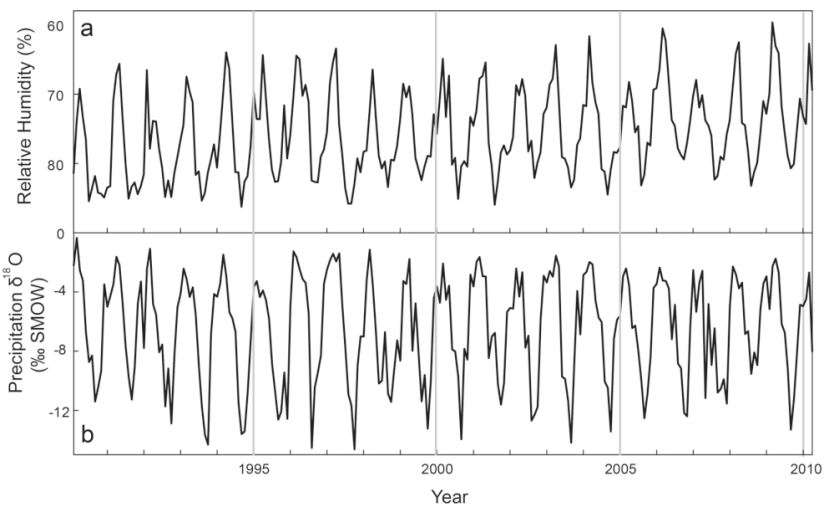

Fig. 4. Two input (a: relative humidity, $b$ : precipitation $\delta^{18} O$ ) parameters for tree ring cellulose oxygen isotope modeling.

measurements of the Merck cellulose were approximately $\pm 0.16 \%$ o $(n=78)$.

\section{Forward modeling}

We hypothesize that the isotope composition of precipitation and relative humidity difference between wet season and dry season is sufficient to generate annual isotope cycles in trees (Fig. 2). We used the Sternberg (2009) model (Eq. (4)) to simulate a theoretical monthly stable oxygen isotope time series, based on local meteorological data (Fig. 2). Modeled isotope time series were then compared with our actual measured $\delta^{18} \mathrm{O}$ chronology from $F$. semicordata and $S$. tonkinensis to test whether annual oxygen isotope cycles exist. Using the Sternberg (2009) model (Eq. (4)) and climate data to simulate tree ring cellulose $\delta^{18} \mathrm{O}$ requires one important assumption: $\delta^{18} \mathrm{O}$ of precipitation is equal to $\delta^{18} \mathrm{O}$ of source water (xylem water).

Model parameters The equilibrium $\left(\varepsilon^{*}\right)$ and kinetic fractionation factors $\left(\varepsilon_{k}\right)$ are regarded as being relatively constant, and have been reported to be approximately $9 \%$ and 29\%o, respectively (Allison et al., 1985). The proportion of isotopic exchange between xylem water and carbohydrate oxygen $\left(f_{\mathrm{o}}\right)$ does not vary at different temperatures (Sternberg and Ellsworth, 2011), and we adopted a previously reported value of 0.42 as the $f_{\mathrm{o}}$ value for our calculations (Roden et al., 2000; Sternberg and Ellsworth, 2011). Although the net biological isotopic fractionation factor between xylem water and exchanged oxygen $\left(\varepsilon_{\mathrm{o}}\right)$ is temperature-sensitive, $\varepsilon_{\mathrm{o}}$ changes little within a temperature range from 20 to $30^{\circ} \mathrm{C}$ (Sternberg and Ellsworth, 2011). Monthly temperature ranged from 18 to $26^{\circ} \mathrm{C}$ at our sampling site, and $\varepsilon_{\mathrm{o}}$ was $27 \%$, as has been observed in previous studies (Sternberg et al., 1984; Sternberg and DeNiro, 1983; Yakir and DeNiro, 1990). Therefore, we used $27 \%$ as the $\varepsilon_{\mathrm{o}}$ value in the model. For the fraction of enriched water $(\alpha)$, values of $67 \%$ to $90 \%$ have been re-

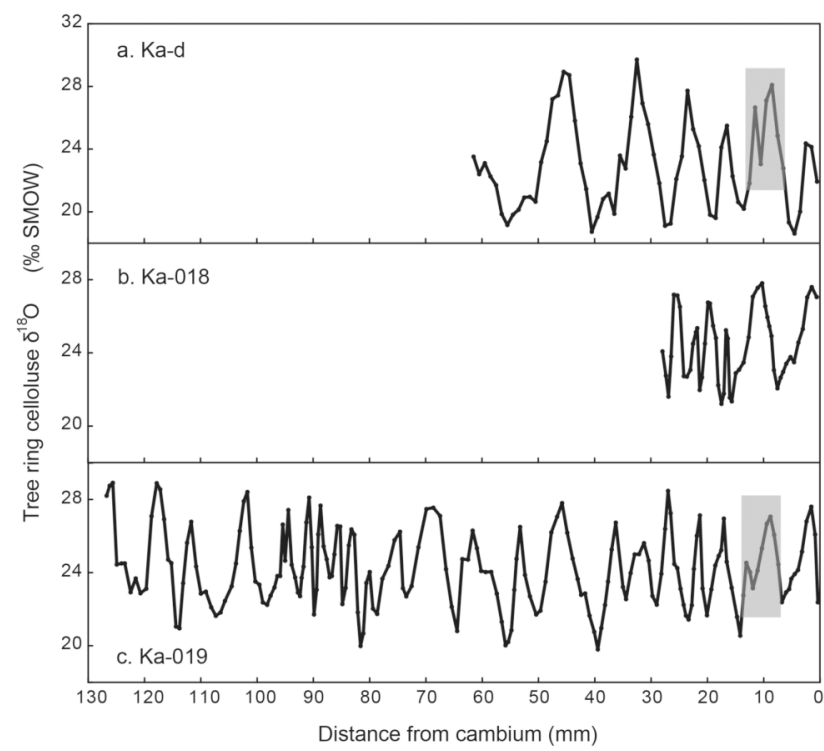

Fig. 5. Radial variations in tree ring cellulose $\delta^{18} O$ in the three samples of Styrax tonkinensis and Ficus semicordata var. semicordata.

ported (Allison et al., 1985; Flanagan et al., 1991; Roden et al., 2000). In our study, the sampling sites are in relatively wet mountainous regions where the Péclet effect does not seem to exert a strong influence on leaf water $\delta^{18} \mathrm{O}$, and we assumed that $\alpha$ is equal to $80 \%$.

Input data Based on Eq. (4), input data required are relative humidity and monthly precipitation $\delta^{18} \mathrm{O}$. Although it is reasonable to assume that daytime mean relative humidity determines the leaf water $\delta^{18} \mathrm{O}$, such data is not available in the study area. Therefore, we used daily mean relative humidity rather than daytime mean relative humidity as an input for the tree ring cellulose $\delta^{18} \mathrm{O}$ model. Monthly relative humidity (Fig. 4a) was recorded by the Muang Xai weather station and Monthly oxygen isotope precipitation data (Fig. 4b) were derived from an Isotopesincorporated Global Spectral Model (IsoGSM) (Yoshimura et al., 2008). We averaged data from two sites that are the nearest grid points $\left(20^{\circ} \mathrm{N}, 101.25^{\circ} \mathrm{E} ; 20^{\circ} \mathrm{N}\right.$, $\left.103.125^{\circ} \mathrm{E}\right)$ to the sampling sites.

\section{RESULTS}

\section{$\delta^{18} O$ of $S$. tonkinensis and F. semicordata}

The samples of $S$. tonkinensis show a distinct annual cyclicity in $\delta^{18} \mathrm{O}$ values (Fig. 5a), with a mean $\delta^{18} \mathrm{O}$ of $22.96 \%$. Minima and maxima in $\delta^{18} \mathrm{O}$ can be distinguished with a mean amplitude of $8.7 \%$. There is a slightly decreasing trend of $\delta^{18} \mathrm{O}$ maxima in the $S$. tonkinensis samples. The mean $\delta^{18} \mathrm{O}$ values of two $F$. semicordata cores (Ka-018 and -019) are 24.22\%o and $24.42 \%$, with a mean amplitude of $\delta^{18} \mathrm{O}$ cycles of $4.8 \%$ o 


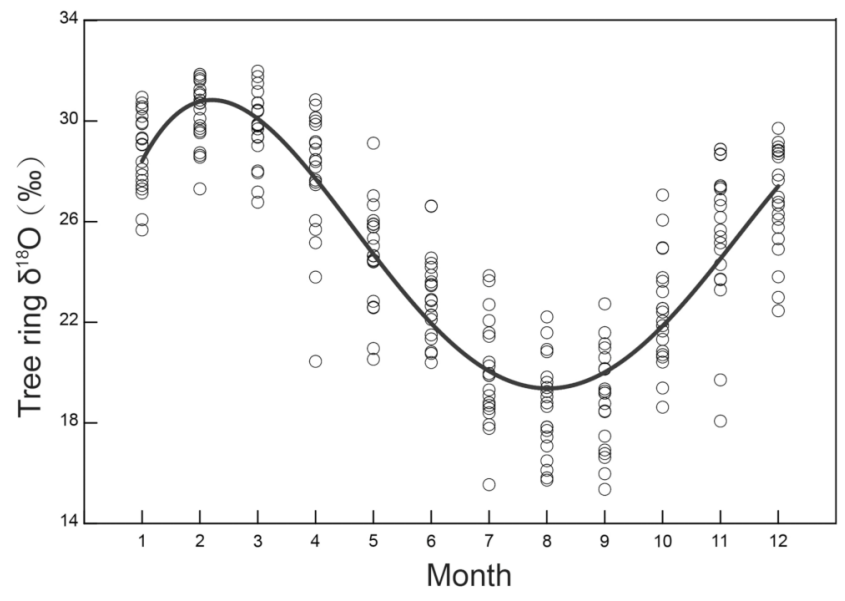

Fig. 6. Monthly variations for modeled tree ring cellulose $\delta^{18} O$.

and 5.1\%o, respectively (Figs. 5b and c). No obvious longterm trend in $\delta^{18} \mathrm{O}$ can be distinguished in the $F$. semicordata cores.

\section{Modeled tree ring cellulose $\delta^{18} O$}

Modeled tree ring cellulose $\delta^{18} \mathrm{O}$ (Figs. 6 and 7) shows clear annual cycles, which are similar to those observed in the measured $\delta^{18} \mathrm{O}$ of the $S$. tonkinensis and $F$. semicordata (Fig. 5). The peak of modeled tree ring $\delta^{18} \mathrm{O}$ values in 1 year typically appears in February/March, with the modeled lowest value being in August/September (Fig. 6). Such annual cycles were also found in northern Thailand and Costa Rica, which has distinct dry and wet seasons (Anchukaitis et al., 2008; Zhu et al., 2012). Based on these cycles, measuring annual growth of trees without clear ring boundaries should be feasible.

To generate a continuous time series for measured tree ring cellulose $\delta^{18} \mathrm{O}$, we developed a simple age model for the tree ring $\delta^{18} \mathrm{O}$ by matching the shape of measured tree ring cellulose $\delta^{18} \mathrm{O}$ with the modeled tree ring cellulose $\delta^{18} \mathrm{O}$ time series, which has been used in previous studies (Anchukaitis et al., 2008; Zhu et al., 2012). We assigned the cellulose $\delta^{18} \mathrm{O}$ maxima of each cycle of tree samples to the month with the highest value for modeled tree ring $\delta^{18} \mathrm{O}$ in a year, and the cellulose $\delta^{18} \mathrm{O}$ minima of each cycle to the month with the lowest modeled tree ring $\delta^{18} \mathrm{O}$ value in a year. From these tie points, adjacent samples are linearly interpolated to monthly resolution. Age models were developed individually for each tree (Fig. 7). The mean inter-series correlation between the monthly $\delta^{18} \mathrm{O}$ series for the three trees is 0.81 , and the correlation between the two F. semicordata cores is 0.87 . Annual radial growth increments of $S$. tonkinensis calculated from the age modeled $\delta^{18} \mathrm{O}$ chronologies revealed a reduction in growth rate, which might be related to the juvenile effect (Fritts, 1976).

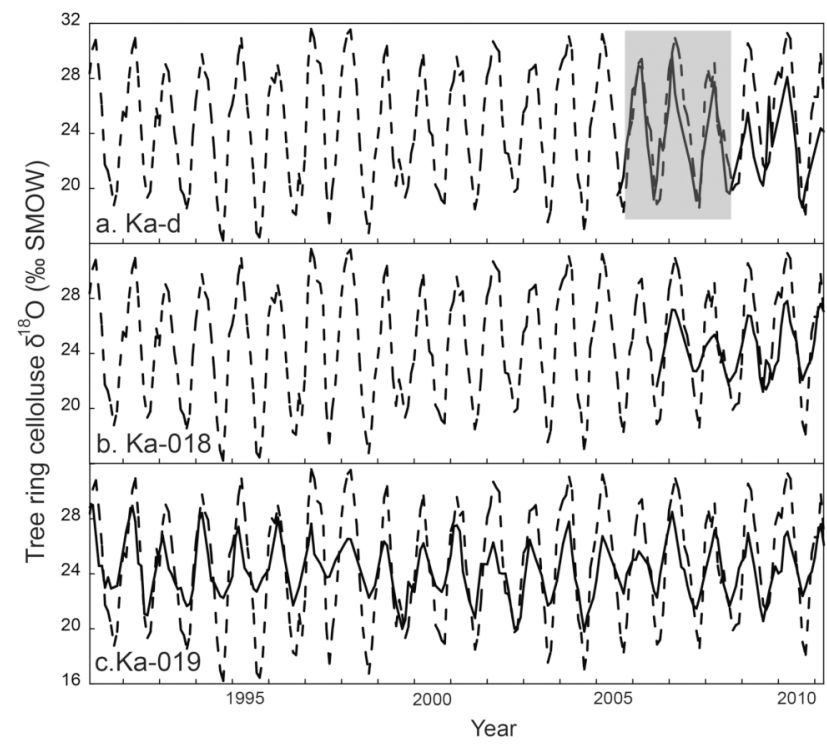

Fig. 7. Comparison between modeled (dashed line) and measured tree ring cellulose $\delta^{18} O$ (solid line).

The correlations between modeled monthly cellulose $\delta^{18} \mathrm{O}$ and observed monthly $\delta^{18} \mathrm{O}$ of Ka-d (S.tonkinensis), $\mathrm{Ka}-018$, and $\mathrm{Ka}-019$ (F. semicordata) are 0.79, 0.77, and 0.84 , respectively. The mean of the modeled $\delta^{18} \mathrm{O}$ is $23.99 \%$, which is close to the observed $\delta^{18} \mathrm{O}$. However, the mean amplitude of the modeled $\delta^{18} \mathrm{O}$ is $11.4 \%$, which is higher than that actually observed.

\section{DISCUSSION}

\section{Annual oxygen isotope cycles}

The cyclical variation of $\delta^{18} \mathrm{O}$ in S. tonkinensis (Fig. 5a) suggests a forcing by seasonally varying environmental conditions. There are six clear $\delta^{18} \mathrm{O}$ cycles, and the $S$. tonkinensis is 7 years old. Considering germination time, $\delta^{18} \mathrm{O}$ cycles in $S$. tonkinensis (Fig. 5a) can be considered to represent annual cycles. $\delta^{18} \mathrm{O}$ cycles of $F$. semicordata show similar features to those of $S$. tonkinensis, although the amplitude of the variations in $F$. semicordata is smaller than S. tonkinensis. Therefore, we also infer that the $\delta^{18} \mathrm{O}$ cycles in $F$. semicordata are annual cycles. Modeled tree ring cellulose $\delta^{18} \mathrm{O}$ also shows distinct annual cycles (Figs. 6 and 7). The formation of tree ring annual $\delta^{18} \mathrm{O}$ cycles is thus dependent on the local climatic conditions (i.e., distinct wet/dry seasons). Based on tree ring cellulose oxygen isotope theory, precipitation $\delta^{18} \mathrm{O}$ and relative humidity are the two main factors controlling tree ring cellulose $\delta^{18} \mathrm{O}$. In the rainy season, low precipitation $\delta^{18} \mathrm{O}$ is a function of both heavy rainfall (amount effect) and high relative humidity (weak evapotranspiration) and results in lower tree ring cellulose $\delta^{18} \mathrm{O}$ (Eq. (4)), and vice versa in the dry season. 
Given that the annual cycles include several apparent growth rings in $F$. semicordata, these apparent rings are clearly not annual in nature. Such growth rings that are not annual rings are also found in Ficus sycomorus in Kenya (Maingi, 2006) and in Cercis siliquastrum in Switzerland (Schweingruber, 2007). Based on the previous study, such recurrent patterns of intra-annual zones are usually genetically determined and modified by environmental factors (Schweingruber, 2007). Daily precipitation data from Muang Xai weather station show the periodic rainfall events during one year, which may lead to these growth rings within one year, because cambial growth was high during high-rainfall season for the trees in Venezuela (Worbes, 1999). To improve understanding on the growth rings of $F$. semicordata, dendrometer and wood anatomy research is needed.

These annual cycles in $\delta^{18} \mathrm{O}$ make it possible to reconstruct an exact chronology and measure annual growth in trees without a clear ring structure. In addition, annual cycles in different species show similar features to some extent. For example, there are two $\delta^{18} \mathrm{O}$ peaks, although one is small and is not an annual cycle, in the year 2010 (shown with gray shading in Fig. 5) for S. tonkinensis (Ka-d) and F. semicordata (Ka-019), which corresponds to two peaks of modeled tree ring $\delta^{18} \mathrm{O}$ in 2010 and indicates that cross-dating by tree ring cellulose $\delta^{18} \mathrm{O}$ is feasible. However, such two peaks pattern in year 2010 in sample Ka-018 is not distinct, although it exists. Therefore, building up a chronology only relying on one time series is challenging and may introduce uncertainties and, as such, several oxygen isotopes time series are required for cross-dating.

The mean $\delta^{18} \mathrm{O}$ value in $S$. tonkinensis is ca. $1.3 \%$ lower than that in $F$. semicordata, whereas the annual amplitude of $\delta^{18} \mathrm{O}$ values in $S$. tonkinensis is about $3.5 \%$ larger than that in F. semicordata. We can infer the following reasons for these differences. Firstly, the $S$. tonkinensis is relatively young and its shallow root system uptakes upper soil water (Vu Dinh Phuong, 1985), whereas the F. semicordata is older than the S. tonkinensis and its relatively deep root system uptakes soil water not only from upper soil water but also from the middle or lower part of the soil profile. Although the exact age of the $F$. semicordata is unknown, we infer that the age of the $F$. semicordata is more than 20 years, based on counting of $\delta^{18} \mathrm{O}$ annual cycles. A $\delta^{18} \mathrm{O}$ study of soil water in southwest China (Luo and Wang, 2008) indicated that the range of $\delta^{18} \mathrm{O}$ of precipitation and $\delta^{18} \mathrm{O}$ of soil water at depths of 50 and $100 \mathrm{~cm}$ are $0 \%$ to $-10 \%,-2 \%$ to $-9.3 \%$, and $-2.7 \%$ to $-8.3 \%$, respectively. This decreasing trend in the amplitude of $\delta^{18} \mathrm{O}$ soil water with depth is brought about by mixing of precipitation from different periods and events. Therefore, the annual amplitude of $\delta^{18} \mathrm{O}$ values in $S$. tonkinensis with a relatively shallow root system is higher than in F. semicordata. Secondly, shorter growing season of $F$. semicordata may lead to smaller amplitude for annual cycles of precipitation $\delta^{18} \mathrm{O}$ that is related to tree ring $\delta^{18} \mathrm{O}$. Thirdly, sampling resolution of F. semicordata is lower than of S. tonkinensis, which may also result in lower annual amplitude of $F$. semicordata. For the difference mean $\delta^{18} \mathrm{O}$ value in $S$. tonkinensis and $F$. semicordata, leaf morphology influences the Péclet effect that is related to leaf water enrichment, and F. semicordata and S. tonkinensis have different leaf morphologies that may lead to the difference in the mean $\delta^{18} \mathrm{O}$ values between the two species (Eq. (4)). Besides, the proportion of isotopic exchange between xylem water and carbohydrate oxygen $\left(f_{\mathrm{o}}\right)$ may vary according to the different species (Li et al., 2011), which could also result in variable mean tree ring $\delta^{18} \mathrm{O}$ values for different species (Eq. (4)).

\section{Comparison between modeled and observed tree ring $\delta^{18} \mathrm{O}$ values}

The modeled cellulose $\delta^{18} \mathrm{O}$ and observed $\delta^{18} \mathrm{O}$ of $S$. tonkinensis and $F$. semicordata show similar variations (Fig. 7). The mean modeled $\delta^{18} \mathrm{O}$ value is $23.99 \%$, which is similar to the observed $\delta^{18} \mathrm{O}$ value. However, the mean amplitude of the modeled $\delta^{18} \mathrm{O}$ is $11.4 \%$, which is higher than that observed. The main reason for this difference may be related to our assumption that the $\delta^{18} \mathrm{O}$ of precipitation is equal to the $\delta^{18} \mathrm{O}$ of the source water. In some cases, $\delta^{18} \mathrm{O}$ values of soil water are much less variable than that of precipitation (Tang and Feng, 2001) as not only the precipitation in a current month, but also that in previous months, will control soil water $\delta^{18} \mathrm{O}$. Given the long residence time of meteoric waters in soil result in temporal mixing of different seasonal water sources, this results in both smoothing and dampening of the amplitude of the annual signal. Therefore, mixing in the soil contributes to the smaller average amplitude of the soil water/tree ring cellulose $\delta^{18} \mathrm{O}$ annual cycles. A previous tree ring cellulose $\delta^{18} \mathrm{O}$ modeling study (Anchukaitis et al., 2008) in Costa Rica also showed that the best match between overall variance in the simulated and actual $\delta^{18} \mathrm{O}$ for experimentally planted trees was achieved using a soil-water mixing ratio of ca. 30:70 (i.e., 30\% new precipitation mixing with $70 \%$ of the previous month's soil water). In addition, if trees absorb not only rainwater, but also underground water, the amplitude of the xylem water $\delta^{18} \mathrm{O}$ annual cycle will be smaller than the amplitude of the precipitation $\delta^{18} \mathrm{O}$ annual cycle.

The amplitude of modeled cellulose and observed $\delta^{18} \mathrm{O}$ values (S. tonkinensis) during the first 3 years (Fig. 7a, gray shading) are very similar, this appears to support our assumption. We can infer that the roots of the young tree are shallow and absorb soil water in the upper part of the soil profile, and that the $\delta^{18} \mathrm{O}$ of upper soil water is 
mainly controlled by recent precipitation. However, the annual amplitude of modeled cellulose $\delta^{18} \mathrm{O}$ is higher than the amplitude of observed $\delta^{18} \mathrm{O}$ values in Ka-d ( $S$. tonkinensis) after the tree is 3 years old, and as the roots become relatively deeper and uptake soil water from the deeper part of the soil profile. Future studies on $\delta^{18} \mathrm{O}$ variations in profiles of soil water with different soil types should be carried out in order to improve the accuracy of tree ring cellulose $\delta^{18} \mathrm{O}$ modeling.

\section{CONCLUSIONS}

We have measured radial variations in tree ring cellulose $\delta^{18} \mathrm{O}$ for $S$. tonkinensis and F. semicordata and identified clear annual cycles. Tree ring cellulose $\delta^{18} \mathrm{O}$ modeling results independently support our detection of $\delta^{18} \mathrm{O}$ annual cycles. Therefore, tree ring cellulose $\delta^{18} \mathrm{O}$ studies have great potential to detect the annual growth of tropical trees that do not exhibit distinct annual rings related to seasonal climate.

Acknowledgments - We are very grateful to Dr. Oh, Mr. Sujan, Mr. Watanabe and Mr. Phommaly for their help to collect treering samples, to Dr. Hirota for him help to identify the tree species. This study was funded by Nagoya University Global COE program and an FS research grant from Research Institute of Humanity and Nature, Kyoto, Japan, grant in-aid for Japan Society for the Promotion of Sciences Fellows (No. 23242047 and 23-10262). We deeply appreciate the helpful comments from two anonymous reviewers to improve the manuscript.

\section{REFERENCES}

Allison, G., Gat, J. and Leaney, F. (1985) The relationship between deuterium and oxygen-18 delta values in leaf water. Chemical Geology: Isotope Geoscience Section 58, 145156.

Anchukaitis, K. J. and Evans, M. N. (2010) Tropical cloud forest climate variability and the demise of the Monteverde golden toad. Proceedings of the National Academy of Sciences 107, 5036-5040.

Anchukaitis, K., Evans, M., Wheelwright, N. and Schrag, D. (2008) Stable isotope chronology and climate signal calibration in neotropical montane cloud forest trees. $J$. Geophys. Res. 113, G03030, doi:10.1029/2007JG000613.

Araguas-Araguas, L., Froehlich, K. and Rozanski, K. (1998) Stable isotope composition of precipitation over southeast Asia. J. Geophys. Res. 103, 28721-28742.

Barbour, M. M., Roden, J. S., Farquhar, G. D. and Ehleringer, J. R. (2004) Expressing leaf water and cellulose oxygen isotope ratios as enrichment above source water reveals evidence of a Peclet effect. Oecologia 138, 426-435.

Bonan, G. B. (2008) Forests and climate change: forcings, feedbacks, and the climate benefits of forests. Science $\mathbf{3 2 0}$, 1444-1449.

Craig, H. and Gordon, L. I. (1965) Deuterium and oxygen 18 variations in the ocean and marine atmosphere. Stable Isotopes in Oceanography Studies and Paleotemperatures, 1222, Lab. di Geol. Nucl., Coniglio Naz. delle Ric., Pisa, Italy.

da Silva, R. P., dos Santos, J., Tribuzy, E. S., Chambers, J. Q., Nakamura, S. and Higuchi, N. (2002) Diameter increment and growth patterns for individual tree growing in Central Amazon Brazil. Forest Ecol. Manag. 166, 295-301.

Dansgaard, W. (1964) Stable isotopes in precipitation. Tellus 16, 436-468.

Dongmann, G., Nürnberg, H., Förstel, H. and Wagener, K. (1974) On the enrichment of $\mathrm{H}_{2}{ }^{18} \mathrm{O}$ in the leaves of transpiring plants. Radiat. Environ. Bioph. 11, 41-52.

Evans, M. and Schrag, D. (2004) A stable isotope-based approach to tropical dendroclimatology. Geochim. Cosmochim. Acta 68, 3295-3305.

Flanagan, L. and Ehleringer, J. (1991) Stable isotope composition of stem and leaf water: applications to the study of plant water use. Funct. Ecol. 5, 270-277.

Flanagan, L. B., Comstock, J. P. and Ehleringer, J. R. (1991) Comparison of modeled and observed environmental influences on the stable oxygen and hydrogen isotope composition of leaf water in Phaseolus vulgaris L. Plant Physiol. 96, 588-596.

Fritts, H. C. (1976) Tree Rings and Climate. Academic, London.

Green, J. (1963) Methods of Carbohydrate Chemistry III (Whistler, R. L., ed.), 9-21, Academic Press, New York.

Li, Q., Nakatsuka, T., Kawamura, K., Liu, Y. and Song, H. (2011) Regional hydroclimate and precipitation $\delta^{18} \mathrm{O}$ revealed in tree-ring cellulose $\delta^{18} \mathrm{O}$ from different tree species in semi-arid Northern China. Chem. Geol. 282, 19-28.

Loader, N., Robertson, I., Barker, A., Switsur, V. and Waterhouse, J. (1997) An improved technique for the batch processing of small wholewood samples to $\alpha$-cellulose. Chem. Geol. 136, 313-317.

Luo, W. J. and Wang, S. J. (2008) Transmission of oxygen isotope signals of precipitation-soil water-drip water and its implications in Liangfeng Cave of Guizhou, China. Chinese Sci. Bull. 53, 3364-3370.

Maingi, J. K. (2006) Growth rings in tree species from the Tana river floodplain, Kenya. Journal of East African Natural History 9, 181-211.

Ohashi, Y., Sahri, M. H., Yoshizawa, N. and Itoh, T. (2005) Annual rhythm of xylem growth in rubberwood (Hevea brasiliensis) trees grown in Malaysia. Holzforschung $\mathbf{5 5}$, 151-154.

Poussart, P. and Schrag, D. (2005) Seasonally resolved stable isotope chronologies from northern Thailand deciduous trees. Earth Planet. Sci. Lett. 235, 752-765.

Roden, J. S., Lin, G. and Ehleringer, J. R. (2000) A mechanistic model for interpretation of hydrogen and oxygen isotope ratios in tree-ring cellulose. Geochim. Cosmochim. Acta 64, 21-35.

Sano, M., Xu, C. and Nakatsuka, T. (2012) A 300-year Vietnam hydroclimate and ENSO variability record reconstructed from tree ring $\delta^{18} \mathrm{O}$. J. Geophys. Res. 117, D12115, doi:10.1029/2012JD017749.

Schweingruber, F. (2007) Wood Structure and Environment. 
Springer-Verlag, Berlin Heidelberg, New York, U.S.A.

Sternberg, L. (2009) Oxygen stable isotope ratios of tree-ring cellulose: the next phase of understanding. New Phytol. 181, 553-562.

Sternberg, L. and DeNiro, M. (1983) Biogeochemical implications of the isotopic equilibrium fractionation factor between the oxygen atoms of acetone and water. Geochim. Cosmochim. Acta 47, 2271-2274.

Sternberg, L. and Ellsworth, P. (2011) Divergent biochemical fractionation, not convergent temperature, explains cellulose oxygen isotope enrichment across latitudes. PloS one 6(11), e28040, doi:10.1371/journal.pone.0028040.

Sternberg, L., Deniro, M. J. and Keeley, J. E. (1984) Hydrogen, oxygen, and carbon isotope ratios of cellulose from submerged aquatic Crassulacean acid metabolism and nonCrassulacean acid metabolism plants. Plant Physiol. 76, 6870.

Tang, K. and Feng, X. (2001) The effect of soil hydrology on the oxygen and hydrogen isotopic compositions of plants' source water. Earth Planet. Sci. Lett. 185, 355-367.

$\mathrm{Vu}$ Dinh Phuong (1985) Some opinions about plantations of Styrax tonkinensis tonkinensis Pierre to provide raw material to the paper industry. Forest Research Institute, Hanoi, Vietnam.

White, J. W. C., Cook, E. R., Lawrence, J. R. and Wallace, S. B. (1985) The ratios of sap in trees: Implications for water sources and tree ring ratios. Geochim. Cosmochim. Acta 49, 237-246.

Worbes, M. (1999) Annual growth rings, rainfall-dependent growth and long-term growth patterns of tropical trees from
Caparo Forest Reserve in Venezuela. J. Ecol. 87, 391-403. $\mathrm{Xu}, \mathrm{C}$., Sano, M. and Nakatsuka, T. (2011) Tree ring cellulose $\delta^{18} \mathrm{O}$ of Fokienia hodginsii in northern Laos: A promising proxy to reconstruct ENSO? J. Geophys. Res. 116, D24109, doi:10.1029/2011JD016694.

Xu, C., Sano, M. and Nakatsuka, T. (2013a) A 400-year record of hydroclimate variability and local ENSO history in northern Southeast Asia inferred from tree-ring $\delta^{18} \mathrm{O}$. Palaeogeography, Palaeoclimatology, Palaeoecology 386, 588-598.

Xu, C., Zheng, H., Nakatsuka, T. and Sano, M. (2013b) Oxygen isotope signatures preserved in tree ring cellulose as a proxy for April-September precipitation in Fujian, the subtropical region of southeast China. J. Geophys. Res. 118, 12805-12815, doi:1002/2013JD01983.

Yakir, D. and DeNiro, M. J. (1990) Oxygen and hydrogen isotope fractionation during cellulose metabolism in Lemna gibba L. Plant Physiol. 93, 325-332.

Yoshimura, K., Kanamitsu, M., Noone, D. and Oki, T. (2008) Historical isotope simulation using Reanalysis atmospheric data. J. Geophys. Res. 113, D19108, doi:10.1029/ 2008JD010074.

Zhu, M., Stott, L., Buckley, B. and Yoshimura, K. (2012) IndoPacific Warm Pool convection and ENSO since 1867 derived from Cambodian pine tree cellulose oxygen isotopes. J. Geophys. Res. 117, D11307, doi:10.1029/2011JD017198.

Zuidema, P. A., Baker, P., Groenendijk, P., Schippers, P., van der Sleen, P., Vlam, M. and Sterck, F. (2013) Tropical forests and global change: filling knowledge gaps. Trends Plant Sci. 18, 413-419. 